J. Lake Sci. (湖泊科学), 2011, 23(1): 122-128

http: //www.jlakes.org. E-mail: jlakes@niglas.ac.cn

(c) 2011 by Journal of Lake Sciences

\title{
高温微风条件下太湖流域风场时空特征分析”
}

\author{
王成林 ${ }^{1,2}$, 黄 娟 $^{3}$, 钱 新 $^{1 * *}$ \\ ( 1 : 南京大学环境学院污染控制与资源化研究国家重点实验室,南京 210093) \\ ( 2 : 解放军理工大学气象学院, 南京 211101) \\ (3:江苏省环境监测中心, 南京 210036)
}

摘 要: 适宜太湖蓝藻水华大面积形成的诸多因素中, 气象因素主要是高温、微风. 据此对太湖周边 17 个常规气象观测 站的 7 年报文资料进行篮选, 选择的 17 个站点同时满足时间为 14 点、气温大于 $25^{\circ} \mathrm{C}$ 、风速小于等于 $4 \mathrm{~m} / \mathrm{s}$ 的风场进行分 析, 研究发现太湖流域风场空间特征以东南风居多, 而且不同风向的背景风场吹过水面后, 在下风向湖面及湖岸附近都 存在明显的辐散, 其散度中心出现在长兴、西山和宜兴构成的三角形区域. 对无锡、宜兴、东山和吴县四个站同时满足上 述条件的天数进行统计分析, 发现太湖流域风场时间特征表现为: 1982 年之前每年高温微风天气出现的天数少而且出现 的时间迟, 而 2004 年之后出现的天数多而且出现的时间早, 在 $1982-2004$ 年之间出现的天数和出现的时间相对于历史 平均值都呈振荡状态.

关键词: 蓝藻水华;EOF; 聚类分析; 热力环流;风场; 辐散;太湖流域

\section{Spatio-temporal characteristics of wind field under high temperature and gentle breeze in Taihu Basin}

WANG Chenglin ${ }^{1,2}$, HUANG Juan ${ }^{3} \&$ QIAN Xin ${ }^{1}$

(1: State Key Laboratory of Pollution Control and Resources Reuse, School of the Environment, Nanjing University, Nanjing 210093 , P. R. China)

(2:PLA University of Science and Technology, School of Meteorology, Nanjing 211101, P. R. China)

(3:Jiangsu Provincial Environmental Monitoring Center, Nanjing 210036, P. R. China)

Abstract: High temperature and gentle breeze were one of the key factors for the algae bloom formation in Lake Taihu. The days when temperature was higher than $25^{\circ} \mathrm{C}$ at $14: 00$ and wind speed was less than $4 \mathrm{~m} / \mathrm{s}$ at the same time were selected, and EOF analysis, cluster analysis of eight directions and divergence spatial distribution were used for studying the wind field from 17 meteorological stations in 2001 - 2007 around Lake Taihu. The spatial characteristics of selected wind field showed that the southeast wind was the major pattern. When any direction wind passed across the lake, the significant divergence appeared above the downwind lake surface and near its banks. The divergence field center was observably in the southwest area of Lake Taihu. Furthermore, statistical analysis on the observational data from 4 meteorological stations, such as Wuxi, Yixing, Dongshan and Wuxian, with days meeting the above-mentioned weather conditions, was put forward during $1961-2007$. The numbers of days with high temperature and gentle breeze per year were less and the beginning time of such weather conditions was later before 1982. Oppositely, the numbers of such days per year was more and the beginning time was earlier after 2004. Both of them showed oscillation during 1982 to 2004.

Keywords: Algae bloom; EOF; cluster analysis; thermal circulation; wind field; divergence; Taihu Basin

* 国家重点基础研究发展计划项目(2008CB418003)、江苏省环境监测科研基金项目(0919)和解放军理工大学基础 理论研究基金项目联合资助. 2010-01-07 收稿;2010-06-12 收修改稿. 王成林, 男, 1977 年生, 博士, 讲师; E-mail: chenglinwang@126.com.

** 通讯作者;E-mail:xqian@ nju. edu. cn. 
太湖位于中国长江中下游地区, 是长江三角洲经济发达地区工业、农业、生活用水的重要水源地. 随着 中国近 30 年的经济迅速发展, 太湖周边经济发达城市 (如无锡、常州、苏州等) 的工业、农业、生活污水不断 汇人太湖,使得太湖水体富营养化. 20 世纪 90 年代至今, 太湖不断出现大面积水华,近几年尤其严重. 2007 年 5 月底无锡市贡湖水厂发生水污染事件,致使无锡市 200 多万人口出现饮用水危机 ${ }^{[1]}$.

目前多数观点认同蓝藻水华的形成一般是由蓝藻本身的生理特点以及气象条件、营养盐、其它生物等 诸多环境因素所引发的 ${ }^{[2]}$. 当太湖富营养化程度没有得到明显控制的情况下, 气象条件对蓝藻生物单体生 长以及水华形成的影响, 显得尤为重要. 吴晓东 ${ }^{[3]}$, 孔繁翔 ${ }^{[2,4]}$ 等研究发现高温、强光照的条件有利于蓝藻 生物体的生长; 孙小静 ${ }^{[5]}$ 、尤本胜 ${ }^{[6]}$ 等研究发现小风浪有利于蓝藻生长或漂浮, 而大风浪对其生长或漂浮不 利. 所以,在营养盐浓度较高的情况下,较长时间维持高温、微风气象条件是蓝藻水华大面积暴发的主要外 因之一.

然而, 太湖有大面积的开敞水域,环湖周边又多为发达城市,在高温、微风气象条件下, 湖区的局地大气 热力环流 (如湖陆风效应 ${ }^{[7-8]}$ 、城市热岛效应 ${ }^{[9]}$ 、山谷风效应 ${ }^{[7]}$ 等) 很明显. 这种局地次级环流叠加在相对较 弱的大尺度背景风场之上,改变了湖面的风场形势. 此时湖面实际风场不再是单一的背景风场, 而是同时受 大尺度背景风场和局地热力环流影响的风场.

因此, 高温、微风气象条件适宜蓝藻生物体的生长, 有利于其从水体中上浮到表层, 形成水华; 其同时也 造成湖面风场分布不一致. 而这种空间有旋的湖面风场必然改变蓝藻水华的漂移路径,对蓝藻水华的预警 起着至关重要的作用.

为此, 本文从气象学角度, 利用历史实测资料分析太湖流域风场的时空特征, 以期证实在高温、微风气 象条件下太湖湖面客观存在气流辐散场; 结合蓝藻水华历史上出现情况,通过分析适宜蓝藻水华形成的气 象条件出现的频次, 解释 2007 年太湖水环境事件形成的气象因素. 从而为蓝藻水华预警提供理论依据和技 术支持.

\section{1 高温微风条件下风场的空间特征}

\section{1 风场的 EOF 分解}

气象常规观测时间点为: 北京时间 08 点、14 点、20 点、02 点. 在这四个观测时次中,最能体现一天中最 高气温和盛行风向的,应该是 14 点. 在夏季高温微风的天气,往往是高压控制. 尤其到了盛夏,太湖区域往 往是副热带高压控制,其一天中风向较为稳定. 只有天气系统过境时,才会出现上、下午风向变化较大的 情况.

为此,选择太湖周边 17 个常规气象观测站 7 年 (2001-2007 年) 报文资料,包括海平面气压、风速、风 向、气温、露点温度、水平能见度、总 云量、中低云累积云量、24h 降水量 9 个要素, 17 个常规气象站的名称和 空间位置见图 1. 从中选择蓝藻水华 易形成的气象条件进行分析,即气温 大于 $25^{\circ} \mathrm{C}$ 、风速小于等于 $4 \mathrm{~m} / \mathrm{s}$ 、观测 时间为北京时间 14 点,得出 17 个站 同时满足条件的有 210 次. 将这 210 次 17 个站点的风场进行经验正交分 解 (Empirical Orthogonal Function, EOF), 实际上就是主成分分析, 详 细原理可参考文献 ${ }^{[10]}$. EOF 分解的 第一模态方差贡献为 $25.5385 \%$, 将 第一模态的纬向和经向风速分别进 行三次样条插值,其流场空间分布见

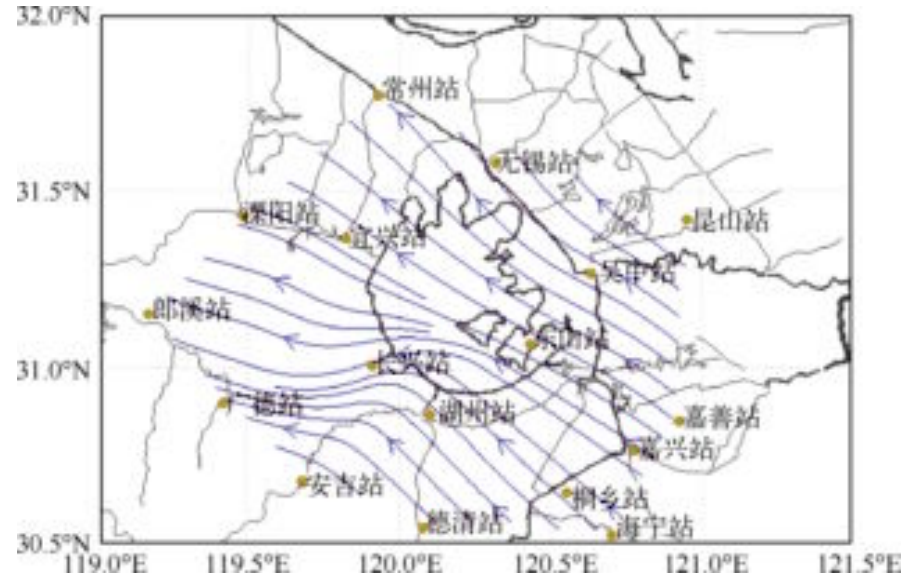

图 1 EOF 分解第一模态空间型

Fig. 1 The first spatial pattern of EOF analysis 
图 1. 太湖流域上游风向为东南风, 东南风吹过湖面在湖心处发生辐散, 在太湖西岸处偏转为东风, 甚至东略 偏北风; 而在太湖的西北岸以及竺山湾、梅梁湾、贡湖湾风向略向南发生偏转, 接近南风(图 1). 因此, 根据 EOF 分解的第一模态空间分布可以得出, 在适宜蓝藻水华形成的气象条件下, 太湖流域主要以东南风居多, 而且东南风吹过湖心水面后, 在太湖西北及湖岸附近存在明显的辐散, 形成与背景风场不一致、太湖区域特 有的风场.

\section{表 1 风场八风向聚类结果}

Tab. 1 The result of eight direction cluster analysis of wind field

\begin{tabular}{ccc}
\hline 分类名称 & 分类标准 & 个例数目 \\
\hline NNE & 无锡站风向为北偏东 $45^{\circ}$ 以内 & 29 \\
$\mathrm{ENE}$ & 无锡站风向为东偏北 $45^{\circ}$ 以内 & 18 \\
$\mathrm{ESE}$ & 东山站风向为东偏南 $45^{\circ}$ 以内 & 50 \\
$\mathrm{SSE}$ & 东山站风向为南偏东 $45^{\circ}$ 以内 & 48 \\
$\mathrm{SSW}$ & 湖州站风向为南偏西 $45^{\circ}$ 以内 & 16 \\
$\mathrm{WSW}$ & 湖州站风向为西偏南 $45^{\circ}$ 以内 & 14 \\
WNW & 宜兴站风向为西偏北 $45^{\circ}$ 以内 & 16 \\
$\mathrm{NNW}$ & 宜兴站风向为北偏西 $45^{\circ}$ 以内 & 40 \\
\hline
\end{tabular}

\section{2 风场的八风向聚类分析}

将上述 210 时次气象条件分为八个方向, 以此分 析不同风向时太湖流域地面大气流场的气候态空间特 征. 八个风向分类是按上游某个测站的风向为标准, 东 北风以无锡站的风向为标准, 当无锡站的风向满足北 偏东 $45^{\circ}$ 以内时, 将此时刻 17 个站的风速、风向归为 NNE 类, 当无锡站的风向满足东偏北 $45^{\circ}$ 以内时, 将此 时刻 17 个站的风速、风向归为 ENE 类; 同理, 东南风以 东山站的风向为选择标准, 分为东偏南 ESE 类和南偏 东 SSE 类; 西南风以湖州站的风向为选择标准, 分为南 偏西 SSW 类和西偏南 WSW 类; 西北风以宜兴站的风 向为选择标准, 分为西偏北 $\mathrm{WNW}$ 类和北偏西 $\mathrm{NNW}$

类. 分类结果见表 1. 在高温、微风的季节, 太湖流域主要盛行东南风 ( ESE 类与 SSE), 共 98 时次, 占 $46.67 \%$; 其次为西北风 ( WNW 类与 NNW), 共计 56 时次,占 $26.67 \%$. 这与上述 $\mathrm{EOF}$ 分解所得结论以及陆鸿 宾等 ${ }^{[8]}$ 的研究结论是一致的.

为此,将同一类中同一个站点的不同时刻的纬向风速和经向风速分别进行算术平均,再对平均的纬向 和经向风速分别进行三次样条插值, 绘制气候态流场空间分布形势 (图 2). 在高温、微风的条件下, 太湖湖 面八个风向风场都发生辐散现象. 这是因为太湖流域沿岸附近多为发达城市和工业区的原因. 在夏季强光 照的条件下,城市和工业区的地表热力作用较太湖湖面水域强得多, 使得这些地区与湖面之间产生较大的 温差, 形成局地次级热力环流. 此热力环流叠加在较弱的背景风场之上, 使得吹过太湖湖面的风场发生了 偏转.

\section{3 平均散度场空间分布}

ESE、SSE 和 NNW 类出现次数最多 (表 1), 对应图 1 中 ESE 图、SSE 图和 NNW 图的风场空间分布形势, 风场发生辐散最为明显的区域在西南太湖. 为此, 对上述 210 个时次空间风场求散度, 再求出散度场的算术 平均值 (图 3). 在高温微风条件下, 太湖湖面风场辐散中心主要集中在长兴、西山和宜兴构成的三角形水 域. 也就是说, 当吹东南风时, 在长兴至宜兴一带的水域风向会辐散成东风甚至东北风, 而在北太湖则辐散 成南风甚至西南风; 当吹西北风时, 在长兴至宜兴一带的水域风向会辐散成北风甚至东北风, 而在东太湖则 辐散成西风甚至西南风. 这与图 1 中 ESE 图、SSE 图和 NNW 图所反映的结论基本一致.

综合上述 3 点分析可以得出, 高温微风条件下太湖流域风场空间特征以东南风居多, 而且不同风向的 背景风场吹过水面后, 在下风向湖面及湖岸附近都存在明显的辐散, 其中在长兴、西山和宜兴构成的三角形 水域辐散出现的最为显著. 蓝藻水华在此风场的驱动下, 其在全湖的分布必然与朱永春 ${ }^{[11-14]}$ 、胡维

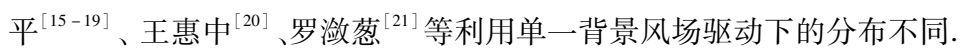

\section{2 高温微风条件下风场的时间特征分析}

对上述 210 次高温微风气象条件出现的时间进行统计,4 月份 2 次, 5 月份 20 次,6 月份 30 次,7 月份 55 次, 8 月份 44 次, 9 月份 43 次, 10 月份 13 次, 11 月份 3 次. 可见,高温、微风天气主要集中出现在 5-9 月份, 其中 7 月份出现次数最多. 而且, 每年出现高温微风的天数有增加的趋势. 为了进一步研究高温微风气象 条件出现的气候尺度特征, 将对 $1961-2007$ 年的报文资料进行分析. 


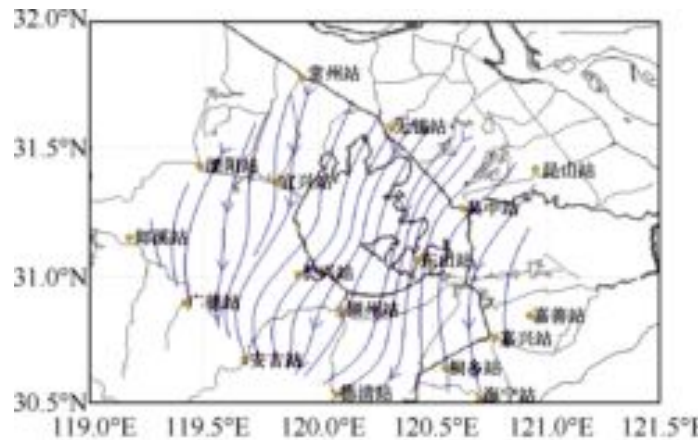
NNE
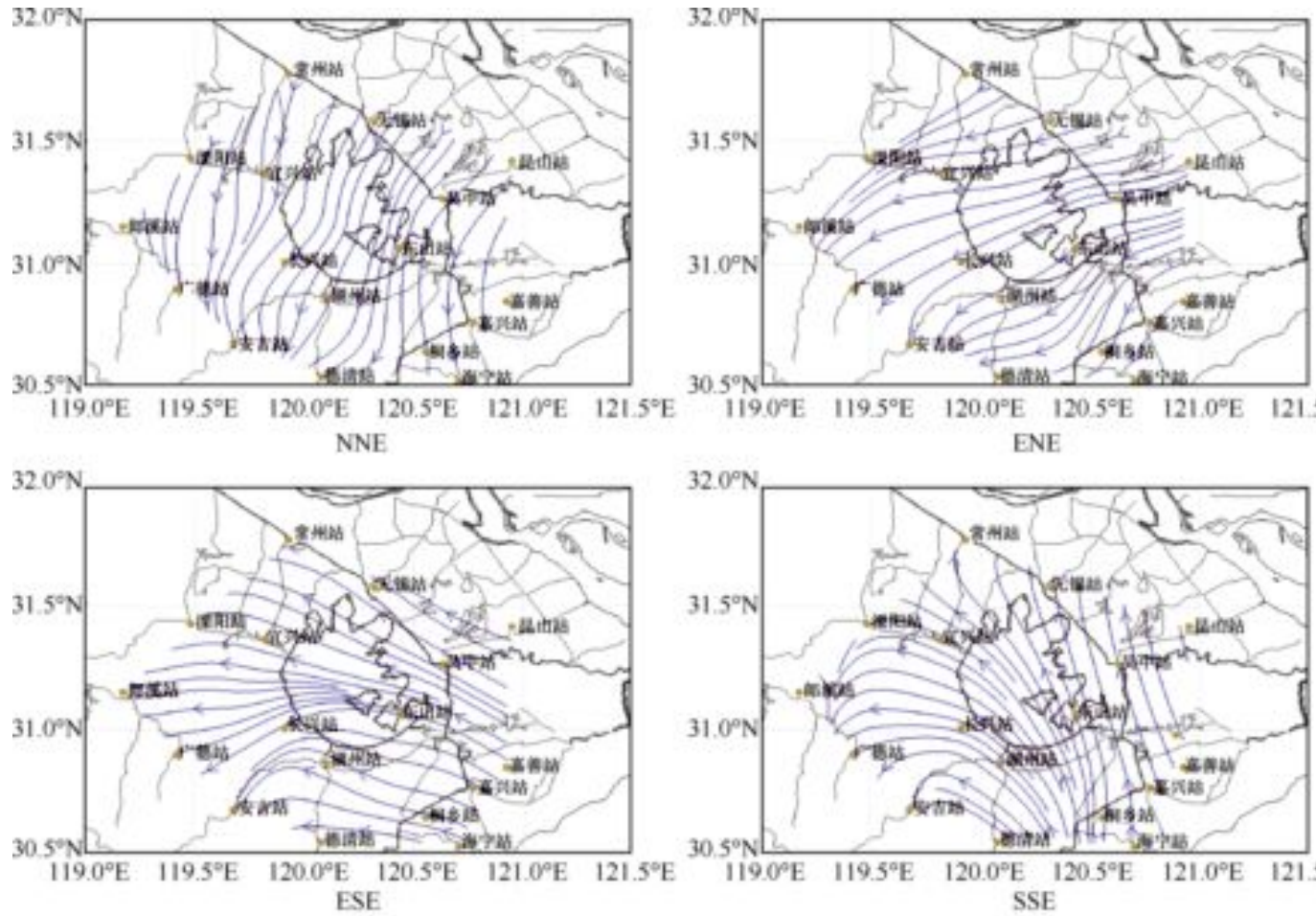

$119.0^{\circ} \mathrm{E} \quad 119.5^{\circ} \mathrm{E} \quad 120.0^{\circ} \mathrm{E} \quad 120.5^{\circ} \mathrm{E} \quad 121.0^{\circ} \mathrm{E} \quad 121.5^{\circ} \mathrm{E}$ ENE
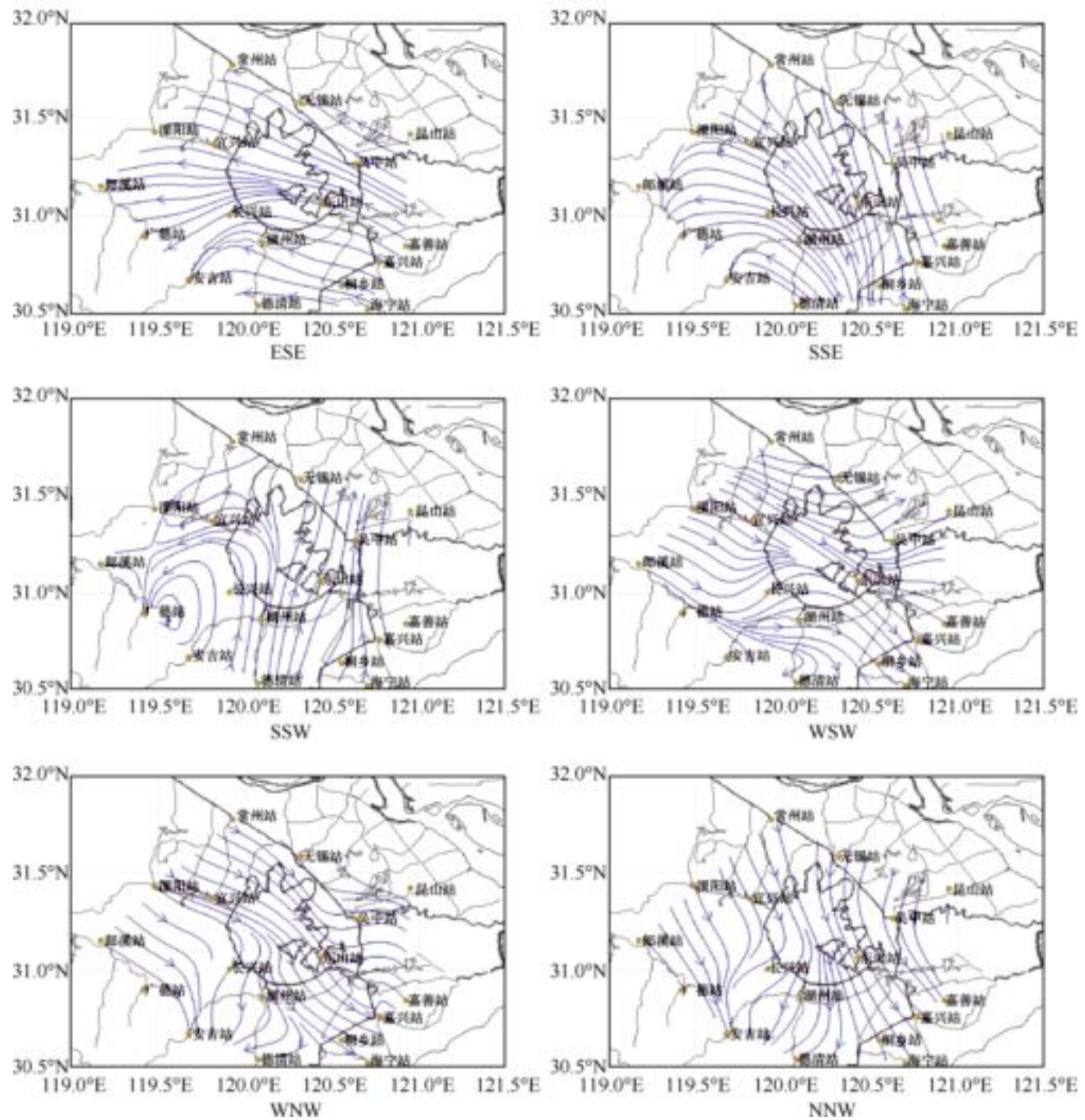

图 2 八个方向的气候态流场分布

Fig. 2 Eight climatic streamline patterns about wind field in the Taihu Basin 


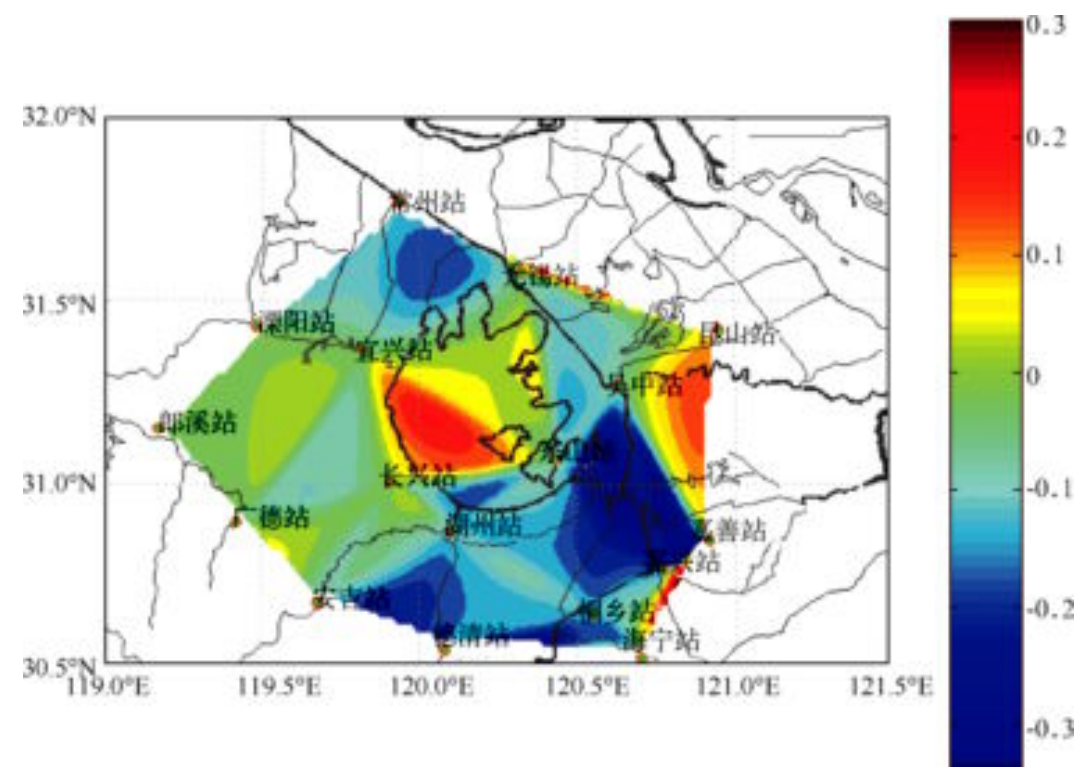

图 3 高温、微风天气风场的平均散度分布

Fig. 3 The spatial pattern of average divergence of wind field with high air temperature and gentle breeze

由于上述 17 个站点中多数站点在 20 世纪 70 年代观测缺值较多, 在此选择太湖周边东山站 (站号: 58358 )、吴中站(站号:58349)、无锡站 (站号:58354)、宜兴站(站号:58346) 的 47 年报文资料, 对同时满足 观测时间为 14 点、气温大于 $25^{\circ} \mathrm{C} 、$ 风速小于等于 $4 \mathrm{~m} / \mathrm{s}$ 的情况进行统计分析. 首先累计满足上述三个条件 的每年总天数, 再对 47 年中每年总天数进行算术平均, 其结果为 $48.2128 \mathrm{~d}$, 近似为 $48 \mathrm{~d}$. 然后求出每年相对 47 年平均值的偏差, 结果可以看出 1982 年之前满足上述三个条件的每年总天数都小于平均值, 之后除了 $1984 、 1985 、 1989 、 1990 、 1992 、 1995 、 2000$ 年略小于平均值之外, 其余年份都大于平均值, 尤其是 2004、2005、 2006 和 2007 年的值较大 (图 4a). 由此可见, 高温微风天气每年出现的频次在 20 世纪 80 年代发生了突变. 这与孙顺才、黄渏平 ${ }^{[22]}$, 谢平、范成新 ${ }^{[23]}$ 对太湖蓝藻水华发生面积的演变趋势描述基本吻合, 这可能是 80 年代之前太湖基本没有出现蓝藻水华现象, 而之后几乎每年都大面积暴发的原因之一.

此外, 2006 年出现高温微风条件的累计天数大于平均值 33d 2007 年大于平均值 $26 \mathrm{~d}$ (图 4a). 依据此 研究结果, 可以得出 2006 年太湖蓝藻水华暴发应该更为严重. 但事实上, 2007 年太湖蓝藻水华暴发较 2006 年造成的灾害和经济损失更为严重, 而且在 2007 年 5 月就暴发了大面积水华, 甚至无锡市 5 月份中下旬就 出现饮用水紧张的现象 ${ }^{[1]}$. 为此, 进一步累计 6 月份之前满足上述三个条件的每年总天数, 再进行算术平 均, 其结果为 $4.7447 \mathrm{~d}$, 近似为 $5 \mathrm{~d} .2007$ 年 6 月份之前出现高温微风的总天数明显大于 2006 年, 共计多 $7 \mathrm{~d}$ (图 4b). 2006 年最早出现高温微风的时间为 4 月 18 日,而 2007 年为 3 月 28 日, 比 2006 年提前了 $18 \mathrm{~d}$ (图 4c). 综合以上结论, 高温微风条件出现时间早、6 月份之前累计出现时间长, 可能是 2007 年蓝藻水华较早 大面积暴发的原因之一.

结合图 4b 与图 4c 还可以看出, 6 月份之前出现高温微风的总天数在 1982 年之前都小于历史平均值 $5 \mathrm{~d}$, 尤其 2004 年以后的连续 4 年都大于历史平均值, 并且这四年最早出现时间都小于历史平均值 5 月初.

因此, 太湖流域高温微风天气出现的频次在 1982 年与 2004 年发生了两次突变, 1982 年之前高温微风 天气出现的总数少而且出现的时间迟; 而 2004 年之后出现的总数多而且出现的时间早; 在 1982-2004 年之 间出现的总天数和出现的时间相对于历史平均值都呈振荡状态.

\section{3 结论与讨论}

本文利用常规气象站的报文资料, 从中选择适宜蓝藻水华形成时的气象条件, 客观分析了太湖湖面的 

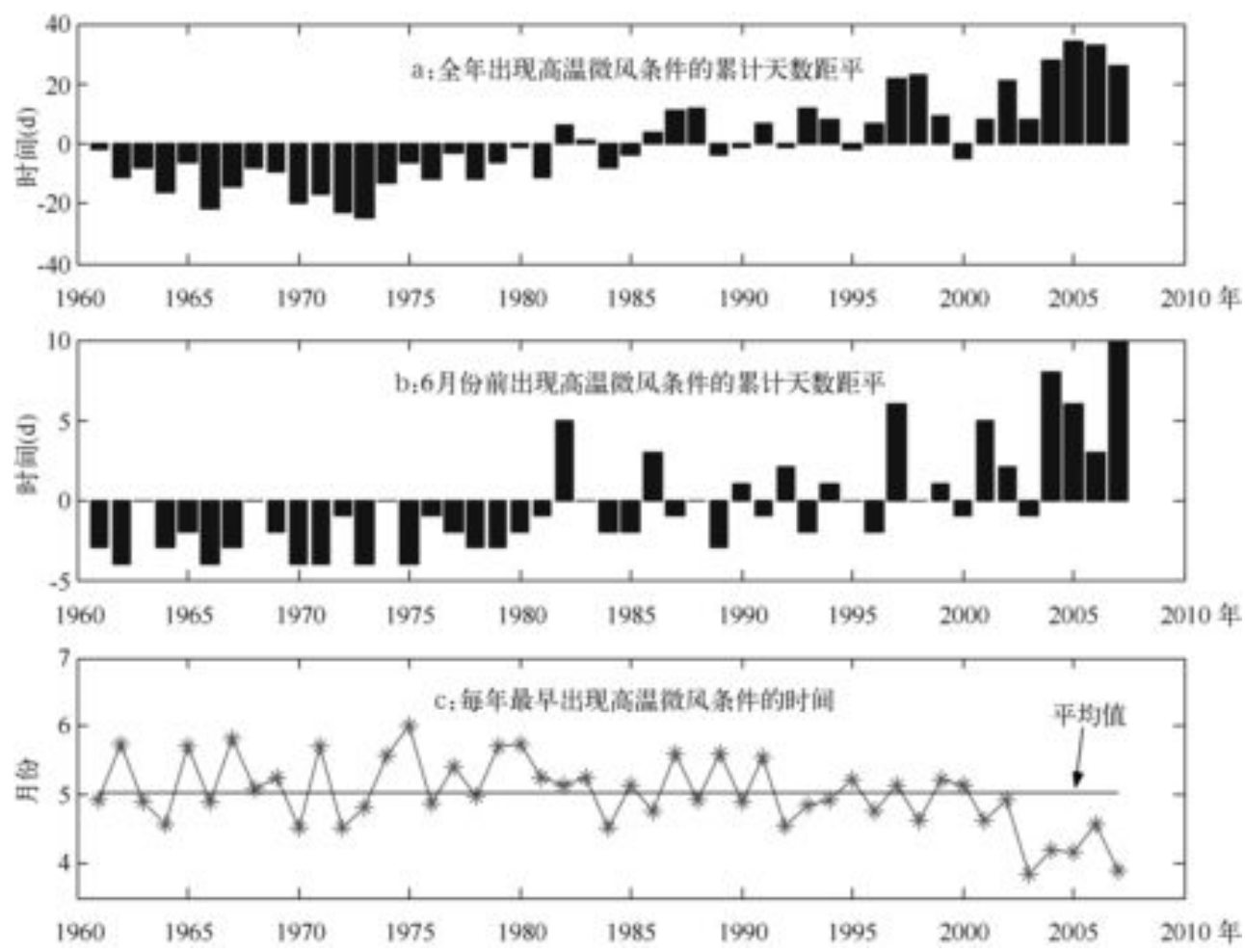

图 4 高温、微风天气累计天数分析

Fig. 4 The analysis of cumulative days under high air temperature and gentle breeze

风场时空特征. 主要得到以下 2 点结论:

(1) 对太湖周边 17 个常规气象观测站的 7 年报文资料进行篮选, 选择 17 个站点同时满足时间为 14 点、气温大于 $25^{\circ} \mathrm{C}$ 、风速小于等于 $4 \mathrm{~m} / \mathrm{s}$ 的风场进行了 EOF 分解、八风向聚类和散度场分布的研究分析, 其 空间特征为, 在形成蓝藻水华的适宜气象条件下, 太湖流域主要以东南风居多, 而且不同风向的背景风场吹 过太湖水面后, 在下风向湖面及湖岸附近存在明显的辐散, 辐散中心集中在长兴、西山和宜兴构成的三角形 水域一带.

(2) 对无锡、宜兴、东山和吴县四个站同时满足上述条件的天数进行统计分析发现, 太湖流域高温微风 天气出现的频次在 1982 年与 2004 年发生了两次突变, 1982 年之前高温微风天气出现的天数少而且出现的 时间迟; 而 2004 之后出现的天数多而且出现的时间早; 在 $1982-2004$ 年之间出现的天数和出现的时间相对 于历史平均值都呈振荡状态. 这可能是 2004 年以来太湖蓝藻水华大面积形成, 并且形成时间较早的重要原 因之一.

上述研究结论表明高温微风时不能用单一的风场驱动水动力模式, 这样会带来较大误差. 目前的中尺 度气象模式能够模拟出高精度的湖面气象要素, 基本能够客观真实反映湖面风场的时空特征. 这必将为水 动力模式提供更为精确的边界气象条件, 大大提高水环境数值模拟的准确度. 另外, 高温微风天气出现的时 间和频次与蓝藻水华大面积形成的时间和面积有着较好的相关性. 所以, 分析高温微风天气出现的时间和 频次对蓝藻水华预警有着重要意义.

\section{4 参考文献}

[ 1 ] 孔繁翔, 胡维平, 谷孝鸿等. 太湖梅梁湾 2007 年蓝藻水华形成及取水口污水团成因分析与应急措施建议. 湖泊 科学, 2007, 19(4):357-358. 
[2] 孔繁翔, 高 光. 大型浅水富营养化湖泊中蓝藻水华形成机理的思考. 生态学报, 2005, 25(3):589-595.

[ 3 ] 吴晓东, 孔繁翔. 水华期间太湖梅梁湾微囊藻原位生长速率的测定. 中国环境科学,2008, 28(6) :552-555.

[ 4 ] 孔繁翔, 马荣华, 高俊峰等. 太湖蓝藻水华的预防、预测和预警的理论与实践. 湖泊科学, 2009, 21(3) :314-328.

[ 5] 孙小静, 秦伯强, 朱广伟等. 风浪对太湖水体中胶体态营养盐和浮游植物的影响. 环境科学, 2007, 28 (3): 506-511.

[6] 尤本胜, 王同成, 范成新等. 风浪作用下太湖草型湖区水体 $N 、 P$ 动态负荷模拟. 中国环境科学, 2008, 28(1):3338.

[ 7 ] 逢 勇,緩培民. 太湖区域三维湖陆风场数值模拟. 大气科学, 1995, 19(2):243-251.

[8] 陆鸿宾,魏桂玲. 太湖的风效应. 气象科学, 1989, 9(3):291-301.

[9] 李维亮,刘洪利,周秀䩀等. 长江三角洲城市热岛与太湖对局地环流影响的分析研究. 中国科学 (D 辑), 2003, 33 (2) :97-104.

[10］黄嘉佑. 气象统计分析与预报方法(第二版). 北京:气象出版社, 2000:135.

[11] 朱永春, 蔡启铭. 风场对藻类在太湖中迁移影响的动力学研究. 湖泊科学, 1997, 9(2):152-158.

[12] 余丰宁, 朱永春, 蔡启铭. 边界层气象条件对水温及水-气界面热交换影响的数值试验. 北京:气象出版社, 1998.

[13] 朱永春, 蔡启铭. 太湖梅梁湾三维水动力学的研究:I. 模型的建立及结果分析. 海洋与湖沼, 1998, 29(1):79-85.

[14] 朱永春, 蔡启铭. 太湖梅梁湾三维水动力学模型的研究: II. 营养盐随三维湖流的扩散规律. 海洋与湖沼, 1998, 29 (2) : 169-174

[15] 胡维平, 誉培民. 太湖水动力学三维数值试验研究: 1. 风生流和风涌增减水的三维数值模拟. 湖泊科学, 1998, 10 (4) : 17-25.

[16] 胡维平, 誉培民. 太湖水动力学三维数值试验研究:2. 典型风场风生流的数值计算. 湖泊科学, 1998, 10(4):2634.

[17] 秦伯强, 胡维平. 太湖梅梁湾水动力及相关过程的研究. 湖泊科学, 2000, 12(4):327-334.

[18] 胡维平, 秦伯强. 太湖水动力学三维数值试验研究: 3. 马山围旺对太湖风生流的影响. 湖泊科学, 2000, 12(4): 335-342.

[19] 胡维平, 秦伯强. 太湖水动力学三维数值试验研究:4. 保守物质输移扩散. 湖泊科学, 2002, 14(4):310-316.

[20] 王惠中, 宋志尧, 薛鸿超. 考虑垂直浴粘系数非均匀分布的太湖风生流准三维数值模型. 湖泊科学, 2001, 13 (3) :233-239.

[21] 罗潋葱, 秦伯强. 基于三维浅水模式的太湖水动力数值试验——盛行风作用下的太湖流场特征. 水动力学研究与 进展 (A 辑), 2003, 18(6):686-691.

[22] 孙顺才, 黄渏平. 太湖. 北京: 海洋出版社, 1993.

[23] 谢 平. 太湖蓝藻的历史发展与水华灾害——为何 2007 年在贡湖水厂出现水污染事件? 30 年能使太湖摆脱蓝 藻威胁吗? 北京: 科学出版社, 2008 . 